\title{
OXYGEN RADICALS IN COMPLEMENT AND NEUTROPHIL-MEDIATED ACUTE LUNG INJURY
}

\author{
Gerd O. TILl and Peter A. WARD \\ Department of Pathology, The University of Michigan Medical School, Ann Arbor, MI 48109-0010, U.S.A.
}

(Received 14 March 1985; Revised 22 March 1985; Accepted 25 March 1985)

\begin{abstract}
The development of experimental acute lung injury following systemic complement activation is closely related to availability of blood neutrophils. Although tissue-destructive neutrophil-derived proteinases may play a supportive role in acute pulmonary injury, it appears that oxygen radical constitute the major neutrophil product responsible for acute damage of lung tissues and cells. Intravascular activation of neutrophils by the chemotactic complement peptide $\mathrm{C5a}$ is related to the generation of superoxide anion. Dismutation of superoxide to hydrogen peroxide and its iron-mediated conversion to hydroxyl radical appear to constitute in vivo events that ultimately lead to acute lung microvascular injury.
\end{abstract}

Keywords-Complement, Neutrophils, Oxygen radicals, Scavengers, Iron chelators, Neutral proteinases, $\alpha_{1}$-antiprotease, Acute lung injury

\section{INTRODUCTION}

Early studies by McCall et al. ${ }^{1}$ have shown that systemic complement activation in rabbits can result in transient neutropenia which was thought to be related to a complement activation product leading to margination and pulmonary sequestration of blood neutrophils. Similar complement-mediated alterations in blood neutrophil kinetics have subsequently been observed in patients during hemodialysis ${ }^{2}$ and in normal donors during nylon fiber leukapheresis. ${ }^{3}$ In both situations, systemic activation of the complement system could be demonstrated. Furthermore, Craddock et al. ${ }^{4}$ provided clinical evidence that complement-mediated sequestration of neutrophils in the lung vasculature is associated with pulmonary dysfunctions and that this may be related to development of the adult respiratory distress syndrome. ${ }^{5}$

The observation that intravenous injection of the complement-derived leukotactic peptide $\mathrm{C} 5 \mathrm{a}$ can cause neutropenia in experimental animals ${ }^{6}$ and that complement-activated serum, when added to endothelial cell cultures in the presence of neutrophils, is able to induce oxygen-radical-dependent lysis of endothelial cells ${ }^{7}$ prompted a series of studies in our laboratory addressing the pathophysiologic role of complement, blood neutrophils, and oxygen radicals in experimental acute lung injury. In the following communication we describe our experimental in vivo models, summarize our findings, and discuss potential pathogenic mechanisms of acute pulmonary injury following systemic complement activation.

\section{ANIMAL MODELS}

Young adult male Long-Evans rats weighing 300 to $400 \mathrm{~g}$ were used. They were anesthetized by an intraperitoneal injection of ketamine hydrochloride $(90 \mathrm{mg}$ / $\mathrm{kg}$ ) and then intravenously injected with $25 \mathrm{U} / \mathrm{kg}$ body weight (in $0.5 \mathrm{ml}$ sterile saline) of purified cobra venom factor (CVF) to induce systemic complement activation. ${ }^{8}$ The measurement of lung injury was determined by the increase in lung vascular permeability, which was estimated by the leakage of ${ }^{125} \mathrm{I}$-labeled bovine serum albumin into the extravascular compartment of the lung. Thirty minutes after CVF injection, animals were sacrificed by exsanguination with aortic transection. One milliliter of blood was collected for assessment of radioactivity. The lung vasculature was then perfused through the right cardiac ventricle with $10 \mathrm{ml}$ phosphate-buffered saline. The lungs were removed and the 
amount of radioactivity remaining within the lung tissue assessed with a gamma scintillation counter. Lung vascular permeability values were calculated as the ratio of radioactivity in the lung to that amount of radioactivity contained in $1.0 \mathrm{ml}$ of blood at the time of sacrifice.

In a second animal model of acute lung injury, different strains of mice were used. ${ }^{9}$ These included: C57B 1/ $\mathrm{J} 6$, beige mice (C57B1/J6, bg $+1+$ ) and their heterozygous controls (C57B1/J6, bg $+1-$ ); and also $\mathrm{B}_{10} \mathrm{D}_{2} /$ Osn and $\mathrm{B}_{10} \mathrm{D}_{2} / N s n$ mice that are C5-deficient and $\mathrm{C} 5$-sufficient, respectively. As in the rat model, lung injury was induced by intravenously injected CVF $(1.0 \mathrm{U} /$ mouse) and measured by the transudation into lung tissues of ${ }^{125} \mathrm{I}$-bovine serum albumin that had been injected intravenously with the CVF. Lung injury was determined by the ratio of the radioactivity remaining in the lungs after vascular perfusion with $2.0 \mathrm{ml}$ saline to the amount of radioactivity present in $100 \mu \mathrm{l}$ blood obtained from the animal at the time of sacrifice ( 30 min post-CVF injection).

A third animal model of acute lung injury was established in thermally injured rats. ${ }^{10}$ Adult male LongEvans rats weighing about 300 to $400 \mathrm{~g}$ were anesthetized with ketamine hydrochloride $(110 \mathrm{mg} / \mathrm{kg})$ and the shaved dorsal skin over the lumbosacral area exposed to $70^{\circ} \mathrm{C}$ water for $30 \mathrm{~s}$. Approximately $30 \%$ of the total body surface area were involved in this nonlethal skin burn. Rats were sacrificed at 3 hours postburn and lung injury determined as described for the CVF model. It has been shown that this type of thermal injury to the skin of rats results in systemic complement activation. ${ }^{10}$

\section{EVIDENCE FOR ROLE OF COMPLEMENT AND NEUTROPHILS IN EXPERIMENTAL ACUTE LUNG INJURY}

In order to investigate whether systemic complement activation caused an increase in lung vascular permeability and morphological changes in lung tissues, rats received a bolus injection of CVF into a peripheral vein. This resulted in a rapid activation of the complement system as evidenced by a loss (within $30 \mathrm{~min}$ ) in hemolytic activity of serum complement, conversion of $\mathrm{C} 3$, decreases in hemolytic activity of individual complement components, and appearance in serum of $\mathrm{C} 5$ derived chemotactic activity which was paralleled by a transient neutropenia. ${ }^{8}$ Morphological examinations of lung tissue sections under light microscopy revealed sequestration of neutrophils in pulmonary vessels. Transmission electron microscopic examinations disclosed large numbers of neutrophils in close contact with vascular endothelium, focal destruction of endothelial cells and basement membrane of pulmonary capillaries, and evidence of fibrin deposits and alveolar hemorrhage. These morphological findings of focal pulmonary microvascular injury were reflected in a 5.7 . fold increase in lung vascular permeability (Table 1).

In the mouse, infusion of CVF into a tail vain resulted in evidence of acute lung injury with a sixfold increase in lung permeability values (Table 2). Nearly identical changes in lung morphology were observed in CVF-treated mice when compared to findings in rats. Transmission electron microscopic examinations of lungs

Table 1. Acute Lung Injury in Rats Following Systemic Complement Activation. Evidence for Role of Neutrophils and Oxygen Radicals

\begin{tabular}{lcc}
\hline Treatment & $\begin{array}{c}\text { Lung Injury (Permeability) } \\
(\bar{X} \pm \text { S.E.M.) }\end{array}$ & $\begin{array}{c}\text { Protection From Lung Injury } \\
\text { (Percentage) }\end{array}$ \\
\hline Saline & $0.16 \pm 0.01$ & - \\
CVF & $0.91 \pm 0.04$ & - \\
CVF + neutrophil depletion & $0.31+0.05$ & 80 \\
CVF + catalase* & $0.32 \pm 0.01$ & 79 \\
CVF + SOD* & $0.46+0.03$ & 60 \\
CVF + DMSO $\dagger$ & $0.32 \pm 0.04$ & 79 \\
CVF + apolactoferrin $\ddagger$ & $0.36+0.03$ & 0 \\
CVF + Fe-lactoferrin $\$$ & $0.92+0.09$ & 0 \\
CVF + FeCl & $1.46+0.04$ &
\end{tabular}

*Catalase and superoxide dismutase (SOD) were injected intraperitoneally ( 10 min prior to CVF injection) at a dosage of $40 \mathrm{mg}(10,000 \mathrm{U} / \mathrm{mg})$ and $30 \mathrm{mg}(4,000 \mathrm{U} / \mathrm{mg})$ per rat, respectively. †Dimethyl sulfoxide $(1.5 \mathrm{ml} / \mathrm{kg}$ body weight) was given intraperitoneally $10 \mathrm{~min}$ prior to $\mathrm{CVF}$ injection.

$\ddagger$ Polyethylene glycol (PEG)-derivatized apolactoferrin (iron-free lactoferrin) was injected intravenously $(100 \mu \mathrm{g} /$ rat) together with CVF.

$\$$ Iron-saturated lactoferrin; dosage and route of injection as apolactoferrin

\#Ferric chloride $(6.0 \mathrm{nmol} / \mathrm{rat})$ was given intravenously together with CVF. 
Table 2. Acute Lung Injury in Mice Following Systemic Complement Activation. Evidence for Role of Neutrophils and Oxygen Radicals

\begin{tabular}{|c|c|c|}
\hline Treatment & $\begin{array}{l}\text { Lung Injury (Permeability) } \\
(\bar{X} \pm \text { S.E.M.) }\end{array}$ & $\begin{array}{l}\text { Protection from Lung Injury } \\
\text { (Percentage) }\end{array}$ \\
\hline Saline (C57 B1) & $0.15 \pm 0.02$ & - \\
\hline CVF (C57 B1) & $0.89 \pm 0.05$ & - \\
\hline CVF + neutrophil depletion & & \\
\hline (C57 B1) & $0.29 \pm 0.05$ & 81 \\
\hline CVF + Catalase $(\mathrm{C} 57 \mathrm{Bl})^{*}$ & $0.43+0.02$ & 62 \\
\hline CVF + SOD $(\text { C57 B } 1)^{*}$ & $0.76 \pm 0.06$ & 18 \\
\hline Saline (beige $+1+$ ) & $0.20 \pm 0.09$ & - \\
\hline Saline (beige $+1-$ ) & $0.20 \pm 0.09$ & - \\
\hline CVF (beige $+1+$ ) & $1.37 \pm 0.10$ & - \\
\hline CVF (beige $+1-$ ) & $1.52 \pm 0.25$ & - \\
\hline Saline $\left(B_{10} D_{2}, C 5\right.$ def.) & $0.15 \pm 0.01$ & - \\
\hline Saline $\left(B_{10} D_{2}, C 5\right.$ suff. $)$ & $0.28 \pm 0.02$ & - \\
\hline CVF $\left(B_{10} D_{2}, C 5\right.$ def. $)$ & $0.17 \pm 0.03$ & - \\
\hline CVF $\left(B_{10} D_{2}, C 5\right.$ suff. $)$ & $0.78 \pm 0.06$ & - \\
\hline
\end{tabular}

*Catalase $(66,000 \mathrm{U} /$ rat $)$ and superoxide dismutase $(66,000 \mathrm{U} /$ rat $)$ were given intravenously together with CVF.

from mice ( $30 \mathrm{~min}$ after CVF injection) revealed prominent aggregates of neutrophils and platelets within the pulmonary interstitial capillaries. Many neutrophils were in direct contact with vascular endothelial cells that showed evidence of cell damage. ${ }^{9}$

In the experimental model of burn injury in rats, intravascular complement activation was observed $(3 \mathrm{~h}$ postburn) by decreases in hemolytic complement activity, reductions in the hemolytic activity of individual complement components, conversion of $\mathrm{C} 3$, and early (at $30 \mathrm{~min}$ postburn) appearance in serum of $\mathrm{C} 5$-derived chemotactic activity. ${ }^{10}$ The presence of chemotactic ac- tivity in serum of thermally injured rats coincided with a drop in the blood neutrophil count, which was probably due to C5a-related aggregation and pulmonary sequestration of neutrophils. Evidence of acute lung injury (at $3 \mathrm{~h}$ postburn) was reflected in a substantial increase (4.5-fold) in lung vascular permeability (Table 3 ) and in morphologic changes, which included neutrophil sequestration in lung capillaries, edema and alveolar hemorrhage.

When rats were depleted either of complement (by intraperitoneal injections of CVF) or blood neutrophils (by intraperitoneal injection of an antiserum against rat

Table 3. Acute Lung Injury in Rats Secondary to Skin Burns. Evidence for Role of Complement, Neutrophils, and Oxygen Radicals

\begin{tabular}{|c|c|c|}
\hline Treatment & $\begin{array}{c}\text { Lung Injury (Permeability) } \\
(\bar{X} \pm \text { S.E.M.) }\end{array}$ & $\begin{array}{l}\text { Protection } \\
\text { (Percentage) }\end{array}$ \\
\hline None & $0.15+0.02$ & - \\
\hline Burn & $0.67+0.04$ & - \\
\hline Burn + complement depletion & $0.20+0.01$ & 90 \\
\hline Burn + neutrophil depletion & $0.19+0.02$ & 92 \\
\hline Burn + catalase* & $0.28+0.05$ & 75 \\
\hline Bum + SOD* & $0.42+0.03$ & 48 \\
\hline Burn + catalase + SOD & $0.20+0.01$ & 90 \\
\hline Burn - DMSO† & $0.28+0.03$ & 75 \\
\hline Burn + DMTU $\ddagger$ & $0.30+0.02$ & 71 \\
\hline Burn + Desferal $\$$ & $0.31+0.01$ & 69 \\
\hline Burn $+\mathrm{Fe}^{3+}$-Desferal $\|$ & $0.65+0.03$ & 4 \\
\hline Burn + 2,3-DHB 9 & $0.34+0.01$ & 63 \\
\hline
\end{tabular}

* Polyethylene glycol-derivatized (PEG) catalase and PEG-superoxide dismutase were injected intravenously ( $10 \mathrm{~min}$ prior to thermal injury) at a dosage of 300 and 450 units, respectively.

$\doteqdot$ Dimethyl sulfoxide ( $1.5 \mathrm{ml} / \mathrm{kg}$ body weight) was given $10 \mathrm{~min}$ prior to thermal injury. $\ddagger$ Dimethyl thiourea $(1000 \mathrm{mg} / \mathrm{kg})$ given intraperitoneally $10 \mathrm{~min}$ prior to burn.

$\$$ Deferrioxamine mesylate $(15 \mathrm{mg} / \mathrm{kg})$ intravenously $10 \mathrm{~min}$ prior to burn.

$\|$ Iron-saturated deferrioxamine: dosage and route of injection as under. ${ }^{4}$

?2,3-dihydroxybenzoic acid $(100 \mathrm{mg} / \mathrm{kg})$ intravenously $10 \mathrm{~min}$ prior to burn. 
neutrophils) prior to thermal injury, lung tissue damage was almost completely prevented ${ }^{10}$ and lung vascular permeability values were significantly diminished (Table 3). Similar protective effects of neutrophil depletion on lung injury were seen in CVF-treated rats and mice (Tables 1 and 2). These observations provide striking evidence that both complement activation products and blood neutrophils are important factors in the pathogenesis of acute lung microvascular injury. Furthermore, studies in C5-deficient mice have indicated that C5 is required for the development of acute lung microvascular injury following intravenous injection of CVF. Lung permeability changes in C5-deficient mice following CVF injection were not significantly different from values obtained in saline-injected control mice, whereas CVF injection into C5-sufficient mice induced profound lung injury (Table 2). These studies suggest that $\mathrm{C5}$ is a critical requirement for the induction of acute lung injury in mice following CVF injection. Although the chemotactic peptide C5a des Arg appears to be the most likely candidate, the complement-activation product(s) responsible in vivo for lung injury in mice (and rats) remains to be identified.

\section{EVIDENCE FOR ROLE OF OXYGEN RADICALS IN ACUTE LUNG INJURY}

It is well accepted that activation of neutrophils by chemotactic or phagocytic stimuli can dramatically increase oxygen uptake and result in the production of highly reactive oxygen metabolites. It appears conceivable that complement-activated neutrophils, when in close contact with lung vascular endothelium, may release toxic oxygen species which can destroy endothelial cells as well as basement membranes. As an experimental approach to answer this question, the effects of superoxide dismutase (SOD) and catalase, scavengers of hydroxyl radical, and iron chelators were tested in experimental animals. It was found that both SOD and catalase protect the pulmonary vasculature from injury following systemic complement activation by CVF in rats and mice (Tables 1 and 2). Similar protective effects were observed in thermally injured rats (Table 3). Treatment of animals with SOD and catalase significantly attenuated the development of the complement and neutrophil-dependent acute lung injury (Table 3). These data provide strong evidence that acute pulmonary injury following systemic complement activation is closely linked to production by lung-sequestered neutrophils of toxic oxygen species.

Although these observations appear to suggest that hydrogen peroxide $\left(\mathrm{H}_{2} \mathrm{O}_{2}\right)$ and superoxide anion $\left(\mathrm{O}_{2}{ }^{-}\right)$ may play a role in acute tissue injury, there is little evidence to suggest that these oxygen metabolites are tissue toxic per se. It appears more likely that a conversion product of $\mathrm{H}_{2} \mathrm{O}_{2}$, perhaps hydroxyl radical $(\cdot \mathrm{OH})$. is the agent responsible for the induction of lung microvascular injury following systemic complement activation. It should also be mentioned that iron plays an essential role in the classic Fenton reaction in which . $\mathrm{OH}$ is formed from $\mathrm{H}_{2} \mathrm{O}_{2}$ :

$$
\begin{aligned}
\mathrm{Fe}^{3+}+\mathrm{O}_{2}^{-} \longrightarrow & \mathrm{Fe}^{2+}+\mathrm{O}_{2} \\
\mathrm{Fe}^{2+}+\mathrm{H}_{2} \mathrm{O}_{2} \longrightarrow & \mathrm{Fe}^{3+}+\mathrm{OH}^{-} \\
+ & \cdot \mathrm{OH} \text { (Fenton reaction) }
\end{aligned}
$$

In order to test for a possible participation of $\cdot \mathrm{OH}$ in the pathogenesis of acute lung injury, experimental animals were pretreated with iron chelators or $\cdot \mathrm{OH}$ scavengers. Pretreatment of CVF-injected rats with the - $\mathrm{OH}$ scavenger, dimethyl sulfoxide, or with the iron chelator apolactoferrin (iron-free lactoferrin) isolated from human milk provided significant dose-dependent protection from complement and neutrophil-mediated acute lung injury. These interventions almost completely prevented increases in lung vascular permeability (Table 1). Morphological examinations revealed normal lung tissues except for the presence of leukoaggregates within lung interstitial capillaries. Endothelial cell damage, fibrin deposition, and intraalveolar hemorrhage were absent. Iron-saturated lactoferrin was devoid of lung-protective effects (Table 1).

Similar protection from lung microvascular injury was also observed in thermally injured rats using iron chelators or hydroxyl radical scavengers. Pretreatment of these animals with iron chelators (deferrioxamine, 2,3-dihydroxybenzoic acid) or $\cdot \mathrm{OH}$ scavengers (dimethyl sulfoxide, dimethyl thiourea) significantly reduced lung vascular permeability (Table 3). Morphological evaluations of protected thermally injured rats showed intrapulmonary sequestration of neutrophils, but no evidence of microvascular injury

\section{NEUTROPHIL PROTEINASES IN ACUTE LUNG INJURY}

As described previously, neutrophils play an essential role in the induction of acute pulmonary injury. Following stimulation by the C5-derived chemotactic peptide, neutrophils not only generate oxygen radicals, but can also release lysosomal enzymes, including neutral proteinases which may as well contribute to lung tissue damage. Granulocytic neutral proteinases, which include elastase, cathepsin G, collagenase, and trypsinlike activity, may, upon their release from neutrophils, digest connective tissue components such as elastin, collagen, and proteoglycans. Neutrophil proteinases released into the extracellular environment are, in most 
instances, very effectively controlled by a system of antiproteinases that includes the very effective $\alpha 1$-proteinase inhibitor. "However, it has been shown that neutrophil-derived oxygen radicals can oxidize the critical methionyl residue in the $\alpha 1$-antiproteinase inhibitor leading to its functional inactivation. ${ }^{12.13}$ This may allow for uncontrolled proteolytic tissue destruction by neutrophil-derived neutral proteinases in oxygen-radical-induced acute lung injury.

To determine the possible role of leukocytic proteinases in acute lung injury, we employed homozygous beige mice (bg $+1+$ ). Neutrophils of these animals virtually lack neutral proteinases. ${ }^{14.15}$ Proteinase sufficient congenic mice with the heterozygous trait ( $b g$ $+1-$ ) served as controls. Our data show that, following CVF injection, the homozygous animals developed extensive lung injury which was not significantly different from that observed in the CVF-injected heterozygous trait (Table 2). These data suggest that the absence of neutral proteinases in neutrophils of beige mice (bg $+/+$ ) confers no protection from acute lung injury following systemic complement activation. In other words, it appears that neutrophil proteinases are not essential (at least during the first $30 \mathrm{~min}$ ) for the expression of acute lung injury in mice.

\section{DISCUSSION}

Our experimental studies have shown that intravenous injection of CVF as well as thermal injury to skin results in systemic activation of the complement system with generation of C5-derived chemotactic activity. This causes blood neutrophils to sequester in pulmonary capillaries where they release oxygen radicals, resulting in acute lung microvascular injury. ${ }^{8,10,16.17}$ Depletion experiments have clearly demonstrated the essential role played by complement-activated neutrophils in the pathogenesis of acute pulmonary injury following systemic complement activity.

Involvement of neutrophil-derived oxygen metabolites in acute tissue damage has also been observed in other experimental models. Johnson and Ward ${ }^{18}$ have shown that treatment of rats with SOD or catalase results in significant protection from immune complexinduced lung injury. Lung protective effects of SOD were seen only in the early phase of acute lung injury. ${ }^{19}$ It was found that SOD decreased the early influx of neutrophils into alveolar spaces, perhaps because the generation of superoxide-inducible chemotactic lipids ${ }^{20.21}$ was suppressed. Following this early SOD-sensitive phase, it was believed that increasing amounts of C5derived chemotactic activity obviated a role for the chemotactic lipids generated by $\mathrm{O}_{2}{ }^{-}$. Because catalase had no suppressive effects on neutrophil accumulation in lung tissue but prevented increases in lung vascular permeability, alveolar hemorrhage, and intraalveolar edema, ${ }^{18}$ it seems likely that $\mathrm{H}_{2} \mathrm{O}_{2}$ or one of its toxic derivatives such as $\mathrm{OH}$ are directly involved in the acute pulmonary injury. Catalase-induced protection against acute lung injury, whether induced by immune complexes, CVF, or skin burn-mediated complement activation, can be explained by its interception of neutrophil-generated $\mathrm{H}_{2} \mathrm{O}_{2}$. Consequently, the generation of highly reactive $\cdot \mathrm{OH}$ is prevented.

As summarized in this communication, there is now increasing experimental evidence to suggest that $\cdot \mathrm{OH}$ is playing an essential role in the pathogenesis of complement and neutrophil-mediated acute tissue injury. This is supported by the observation that $\cdot \mathrm{OH}$ scavengers exhibited strong protective effects in the CVF as well as in the thermal injury model of acute lung injury. ${ }^{16.17}$ Furthermore, pretreatment of experimental animals with iron chelators also significantly reduced pulmonary transudation of intravenously injected radiolabeled serum albumin and prevented lung tissue damage as evidenced by transmission electron microscopy. As would be expected, complement-dependent immune complex-induced vasculitis in rats follows a similar pattern with attenuation of the vascular injury by pretreatment of the experimental animals with iron chelators or $\cdot \mathrm{OH}$ scavengers. ${ }^{22}$ It is assumed that iron chelators interfere with the iron-mediated conversion of $\mathrm{H}_{2} \mathrm{O}_{2}$ to $\cdot \mathrm{OH}$, thus preventing acute tissue damage. Accordingly, iron-saturated chelators showed no protection, and infusion of nanomolar amounts of ferric chloride actually enhanced complement and neutrophilmediated acute lung injury and immune vasculitis. ${ }^{17.22}$

Whether neutrophil-derived neutral proteinases play a significant role in complement-mediated acute lung injury remains speculative. Johnson and Ward ${ }^{18}$ have shown that intraalveolar treatment of rats with large doses of antiproteinases does not inhibit or ameliorate oxygen-radical-mediated acute immune complex lung injury. In addition, beige mice, which almost completely lack neutrophil elastase, showed the same degree of CVF-induced acute lung injury ${ }^{9}$ and dermal immune vasculitis ${ }^{15}$ as did congenic elastase-sufficient mice. Furthermore, the newly discovered enzyme, methionine sulfoxide-peptide reductase, ${ }^{23}$ present in human neutrophils, alveolar type Il epithelial cells, and lung homogenates, which can reduce methionine sulfoxide to methionine and thus reactivate oxidized $\alpha 1$ antiprotease, may, at least in the human lung, prevent a significant loss of the antiproteinase shield. However, the picture appears to be even more complex. Proteinase inhibitors may exert additional antiinflammatory effects through scavenging of oxygen radicals and direct inhibition of neutrophil enzymes involved in the 
production of oxygen radicals. ${ }^{24}$ On the other hand, leukocytic extracts (elastase, cathepsin $G$ ) have been shown to prime macrophages for enhanced release of $\mathrm{O}_{2}{ }^{-}$and $\mathrm{H}_{2} \mathrm{O}_{2} \cdot{ }^{25}$ The latter product may in turn interact with various protein substrates to render them more susceptible to proteolysis by leukocytic extracts. ${ }^{26}$ Taken together, these observations seem to add little support for proteolysis being a significant mechanism in acute tissue damage, but appear to widen and further emphasize the important pathogenic role of oxygen radicals in complement and neutrophil mediated acute lung injury.

Acknowledgements - This paper was presented as a Research Progress Report at the Great Lakes Workshop on Oxygen Radicals in Medicine and Biology held at Michigan State University, East Lansing, Michigan, November 1-2, 1984, chaired by Steven D. Aust. Supported in part by NIH Grants GM-29507, GM-28499, HL28442, and HL-31963

\section{REFERENCES}

1. C. E. McCall, L. R. DeChatelet, D. Brown, and P. Lachmann. New biological activity following intravascular activation of the complement cascade. Nature 249: 841-843 (1974).

2. P. R. Craddock, H. Fehr, A. P. Dalmasso, K. L. Brigham, and H. S. Jacob. Hemodialysis leukopenia. Pulmonary vascular leukostasis resulting from complement activation by dialyzer cellophane membranes. J. Clin. Invest. 59: 879-888 (1977).

3. J. Nusbacher, S. I. Rosenfeld, J. L. MacPherson, P. A. Thiem, and J. P. Leddy. Nylon fiber leukapheresis-associated complement component changes and granulocytopenia. Blood 51: 359365 (1978).

4. P. R. Craddock, J. Fehr, K. L. Brigham, R. S. Kronenberg, and H. S. Jacob. Complement and leukocyte-mediated pulmonary dysfunction in hemodialysis. New Engl. J. Med. 269: 769-774 (1977).

5. D. E. Hammerschmidt, L. J. Weaver, L. D. Hudson, P. R. Craddock, and H. S. Jacob. Association of complement activation and elevated plasma-C5a with adult respiratory distress syndrome: Pathophysiological relevance and possible prognostic value. Lancet 1: 947-949 (1980).

6. J. T. O'Flaherty, H. Showell, and P. A. Ward. Neutropenia induced by systemic infusion of chemotactic factors. J. Immunol. 118: 1586-1589 (1977).

7. T. Sacks, C. F. Moldow, P. R. Craddock, T. K. Bowers, and H. S. Jacob. Oxygen-radical mediated endothelial cell damage by complement-stimulated granulocytes: An in vitro model of immune vascular damage. J. Clin. Invest. 61: 1161-1167 (1978).

8. G. O. Till, K. J. Johnson, R. Kunkel, and P. A. Ward. Intravascular activation of complement and acute lung injury: Dependency on neutrophils and toxic oxygen metabolites. J. C/in. Invest. 69: 1126-1135 (1982).

9. H. W. Tvedten, G. O. Till, and P. A. Ward. Mediators of lung injury in mice following systemic activation of complement. Amer. J. Pathol. 119: 92-100 (1985).
10. G. O. Till, C. Beauchamp, D. Menapace, W. Tourtellotte. R Kunkel, K. J. Johnson, and P. A. Ward. Oxygen radical-dependent lung damage following thermal injury to rat skin. $J$. Trauma 28:269-277 (1983).

11. H. Carp and A. Janoff. Modulation of inflammatory cell protease-tissue antiprotease interactions at sites of inflammation by leukocyte-derived oxidants. Adv. Inflammation Res. 5: 173-201 (1983).

12. D. Johnson and J. Travis. Structural evidence for methionine at the reactive site of human $\alpha 1$-protease inhibitor. J. Bio. Chem. 253: $7142-7144$ (1978).

13. H. Carp and A. Janoff. In vitro suppression of serum elastaseinhibitory capacity by reactive oxygen species generated by phagoxytosing polymorphonuclear leukocytes. J. Clin. Invest. 63: 793-797 (1979)

14. V. J. Vassalli, A. P. Granelli, C. Griscelli, and E. Reich. Specific protease deficiency in polymorphonuclear leukocytes of Chediak-Higashi syndrome and beige mice. J. Exp. Med. 147: 12851293 (1978)

15. K. J. Johnson, J. Varani, J. Oliver, and P. A. Ward. Immunologic vasculitis in beige mice with deficiency of leukocytic neutral protease. J. Immunol. 122: 1807-1811 (1979)

16. G. O. Till, J. R. Hatherill, W. W. Tourtellotte, M. J. Lutz, and P. A. Ward. Lipid peroxidation and acute lung injury following thermal trauma to skin: Evidence for role of hydroxyl radical. Amer. J. Pathol. (in press).

17. P. A. Ward, G. O. Till, R. Kunkel, and C. Beauchamp. Evidence for role of hydroxyl radical in complement and neutrophil-dependent tissue injury. J. Clin. Invest. 72: 789-801 (1983).

18. K. J. Johnson and P. A. Ward. Role of oxygen metabolites in immune complex injury of lung. J. Immunol. 126: 2365-2369 (1981).

19. J. R. McCormick, M. M. Harkin, K. J. Johnson, and P. A. Ward. Suppression by superoxide dismutase of immune-complex-induced pulmonary alveolitis and dermal inflammation. Amer. J. Pathol. 102: 55-61 (1981).

20. H. D. Perez, B. B. Weksler, and I. A. Goldstein. Generation of a chemotatic lipid from arachidonic acid by exposure to a superoxide-generating system. Inflammation 4: 313-328 (1980).

21. W. F. Petrone, D. K. English, K. Wong, and J. M. McCord. Free radicals and inflammation: The superoxide-dependent activation of a neutrophil chemotactic factor in plasma. Proc. Nat Acad. Sci. USA 77: 1159-1163 (1980).

22. S. E. G. Fligiel, P. A. Ward, K. J. Johnson, and G. O. Till Evidence for a role of hydroxyl radical in immune complexinduced vasculitis. Amer. J. Pathol. 115: 275-382 (1984)

23. H. Carp, A. Janoff, W. Abrams, G. Weinbaum, R. T. Drew. H. Weisbach, and N. Brot. Human methionine sulfoxide-peptide reductase, an enzyme capable of reactivating oxidized $\alpha$ l-proteinase inhibitor in vitro. Amer. Rev. Resp. Dis. 127: 301-305 (1983).

24. D. M. Shasby. Antioxidant activity of some antiproteases. Amer Rev. Resp. Dis. 131: 293 294 (1985)

25. C. P. Speer, M. J. Pabst, H. B. Hedegaard, R. F. Rest, and R. B. Johnston. Enhanced release of oxygen metabolites by monocyte-derived macrophages exposed to proteolytic enzymes: Activity of neutrophil elastase and cathepsin G. J. Immunol. 133: 2151-2156 (1984).

26. S. E. G. Fligiel, E. C. Lee, J. P. McCoy, K. J. Johnson, and J. Varani. Protein degradation following treatment with hydrogen peroxide. Am. J. Pathol. 115: 418-425 (1984). 